\title{
Synthesis, characterization and electrochemical-sensor applications of zinc oxide/graphene oxide nanocomposite
}

\author{
Ehab Salih $^{1} \cdot$ Moataz Mekawy $^{1} \cdot$ Rabeay Y. A. Hassan ${ }^{2}$ (1) $\cdot$ Ibrahim M. El-Sherbiny $^{1}$
}

Received: 29 October 2015/ Accepted: 6 February 2016/Published online: 19 February 2016

(C) The Author(s) 2016. This article is published with open access at Springerlink.com

\begin{abstract}
Nanostructured metal oxides received considerable research attention due to their unique properties that can be used for designing advanced nanodevices. Thus, in the present study, zinc oxide/graphene oxide ( $\mathrm{ZnO} / \mathrm{GO})$ nanocomposite was synthesized, characterized and implemented in an electrochemical system. The formation of a compacted $\mathrm{ZnO} / \mathrm{GO}$ nanocomposite was confirmed by field emission scanning electron microscopy, high-resolution transmission electron microscopy (HRTEM), X-ray diffraction (XRD), and attenuated total reflectance spectroscopy. HRTEM showed that $\mathrm{ZnO}$ nanocrystals (NCs) are well formed on the GO surface and are interconnected via GO functional groups. From the XRD patterns, the average size of $\mathrm{ZnO} \mathrm{NCs}$ was found to be about $21.7 \pm 2.3 \mathrm{~nm}$ which is in agreement with the HRTEM results. The newly developed nanocomposite-based electrochemical system showed a significant improvement in both electrical conductivity and the electrocatalytic activity as noted from the cyclic voltammetry measurements. Consequently, direct electron transfer efficiency was confirmed and used for the amperometric detection of hydrogen peroxide $\left(\mathrm{H}_{2} \mathrm{O}_{2}\right)$. Fast and sensitive electrochemical responses for the detection of $\mathrm{H}_{2} \mathrm{O}_{2}$ at $1.1 \mathrm{~V}$ in the linear
\end{abstract}

Electronic supplementary material The online version of this article (doi:10.1007/s40097-016-0188-z) contains supplementary material, which is available to authorized users.

Rabeay Y. A. Hassan

rabeayy@yahoo.com; rabeayy@gmail.com

1 Center for Materials Science, Zewail City of Science and Technology, 6th October City, Giza 12588, Egypt

2 Microanalysis Lab, Applied Organic Chemistry Department, National Research Centre (NRC), El-Buhouth St., Dokki, Cairo 12622, Egypt response range from 1 to $15 \mathrm{mM}$ with the detection limit $(\mathrm{S} / \mathrm{N}=3)$ of $0.8 \mathrm{mM}$ were obtained. These results demonstrated that the prepared $\mathrm{ZnO} / \mathrm{GO} / \mathrm{CPE}$ displayed a good performance along with high sensitivity and longterm stability.

Keywords Electrochemical biosensors .

Nanocomposite $\cdot$ Zinc oxide/graphene oxide composites . Hydrogen peroxide detection

\section{Introduction}

Electrochemical techniques have recently showed many advantages in medical and biological analysis such as high sensitivity, low cost, rapid response, and simplicity [1]. In the era of nanomaterials, several electrochemical systems have been developed using various nanomaterials such as nanostructured metal oxides [2]. Amongst the nanostructured metal oxides, zinc oxide semiconductor nanocrystals ( $\mathrm{ZnO} \mathrm{NCs}$ ) have been widely used in photocatalytic [3], photonic [4] spintronic [5], and many other optoelectronic applications [6]. This could be attributed to their wide band gap $(3.37 \mathrm{eV})$ and large excitonic binding energy $(60 \mathrm{meV})[7,8]$. However, the use of $\mathrm{ZnO} \mathrm{NCs}$ as a single electrode modifier in electrochemical biosensors is limited since it behaves as n-type semiconductor. This causes fast recombination of the generated electron-hall pairs and low operating speed, and thus, the capability of direct electron transfer is rather difficult [9]. Instead, implementation of artificial electron shuttles [10] or using hydride substances [11] to liberate the captured-(stored)-electrons is highly recommended.

To avoid the utilization of artificial redox mediators, the direct electrochemical communication is more preferable. 
Thus, the integration (or hybridization) of $\mathrm{ZnO}$ with other carbon-based materials has been reported $[12,13]$. Due to its interesting mechanical and electrochemical properties, and the ease of its mass production in addition to the abundance of several function groups on its surface [12, 14], graphene oxide (GO) has attracted our attention to build up sensitive and reliable electrochemical sensors and biosensors. In fact the interesting catalytic activity of the $\mathrm{ZnO} / \mathrm{GO}$ nano-structured has been shown in several electrochemical applications [15-20]. However, better understanding for the mechanisms behind the use of either the composite or its elemental composition (i.e. individual use of $\mathrm{ZnO}$ NPs, or GO NPs) for the direct electron transfer is still unclear.

Therefore, the main concern of this study is to identify the possibility of direct electrochemical uses of $\mathrm{ZnO} / \mathrm{GO}$ nanocomposite. To reach that goal, fabrication with full characterization of $\mathrm{ZnO} / \mathrm{GO}$ nanocomposite was performed. Electrocatalytic activity of the target nanostructure was investigated using the redox functions of ferricyanide (FCN). In addition, direct electrochemical detections were performed after testing the role of $\mathrm{ZnO}$ alone or upon combination with $\mathrm{GO}$ in form of a nanocomposite. Consequently, the modified electrode with the nanocomposite was successfully used for the direct amperometric determination of hydrogen peroxide, as one of the most important biomarkers for several biochemical process and enzymatic functions [21, 22]. The developed $\mathrm{ZnO} / \mathrm{GO}$ modified CPE presents high sensitivity, low potential and long-term stability towards the detection of $\mathrm{H}_{2} \mathrm{O}_{2}$, which could be a promising approach for the development of nonenzymatic $\mathrm{H}_{2} \mathrm{O}_{2}$ sensor.

\section{Materials and methods}

\section{Materials}

Graphite flakes were purchased from Fisher (UK), chemical reagents such as sulfuric acid $\left(\mathrm{H}_{2} \mathrm{SO}_{4}\right)$, phosphoric acid $\left(\mathrm{H}_{3} \mathrm{PO}_{4}\right)$, potassium permanganate $\left(\mathrm{KMnO}_{4}\right)$, hydrogen peroxide $\left(\mathrm{H}_{2} \mathrm{O}_{2}\right)$, dimethylformamide (DMF), Zinc acetate dihydrate $\mathrm{Zn}\left(\mathrm{CH}_{3} \mathrm{COO}\right)_{2} \cdot 2 \mathrm{H}_{2} \mathrm{O}$, phosphate buffer saline (PBS) were purchased from Sigma-Aldrich (Germany).

\section{Methods}

\section{Preparation of $G O$}

GO was prepared using improved Hummer method with a slight modification [23]. Typically, $3 \mathrm{~g}$ of graphite flakes was added to a $4: 1$ mixture of concentrated $\mathrm{H}_{2} \mathrm{SO}_{4} / \mathrm{H}_{3} \mathrm{PO}_{4}$ (160:40 mL), $15 \mathrm{~g}$ of $\mathrm{KMnO}_{4}$ was added to the mixture with keeping the temperature below $5^{\circ} \mathrm{C}$ using ice bath. The reaction was heated to $60{ }^{\circ} \mathrm{C}$ with stirring for $24 \mathrm{~h}$. Finally, the reaction was cooled to room temperature and poured onto ice $(\sim 400 \mathrm{~mL})$ with $30 \% \mathrm{H}_{2} \mathrm{O}_{2}(5 \mathrm{~mL})$. The resulting solution was maintained at room temperature overnight and then the supernatant was decanted away. This process was repeated for 4 days. Afterwards, the dispersion was washed repeatedly with water in a cycle of centrifugation and decantation, and finally washed with ethanol. The product was allowed to dry at $50{ }^{\circ} \mathrm{C}$ for $12 \mathrm{~h}$.

\section{Preparation of $\mathrm{ZnO/GO}$ nanocomposite}

In a typical procedure, $10 \mathrm{mg}$ GO was first dispersed in $10 \mathrm{~mL}$ of DMF by sonication for $4 \mathrm{~min}$. Then, the GO suspension was added with stirring to $50 \mathrm{~mL}$ of zinc acetate dihydrate $\left[\mathrm{Zn}\left(\mathrm{CH}_{3} \mathrm{COO}\right)_{2} \cdot 2 \mathrm{H}_{2} \mathrm{O}\right]$ dissolved in DMF (0.02 M). Subsequently, the mixture was heated to $90{ }^{\circ} \mathrm{C}$ and maintained at that temperature for $5 \mathrm{~h}$. The color of the resulting $\mathrm{ZnO} / \mathrm{GO}$ powder was then changed into grayishwhite. The product was subjected to repeated washing with ethanol followed by centrifugation, and finally washing with water. The pure $\mathrm{ZnO} / \mathrm{GO}$ powder was obtained after drying the product overnight at $50{ }^{\circ} \mathrm{C}$. $\mathrm{ZnO} \mathrm{NCs}$ were prepared using the same procedure and used as the control sample.

\section{Morphological characterization}

Attenuated total reflectance (ATR) spectroscopy of the produced $\mathrm{ZnO} / \mathrm{GO}$ nanocomposite was performed using FTIR spectrometer (NECOLET iS10). The morphology of $\mathrm{ZnO} / \mathrm{GO}$ nanocomposites was investigated by HRTEM (JEOL -JEM- 2100) at an accelerating voltage of $200 \mathrm{kV}$. Field emission scanning electron microscope FESEM images were carried out using a (Nova Nano SEM 450) at an accelerating applied potential of $15 \mathrm{keV}$. The X-ray diffraction patterns of the samples were recorded by X-ray diffractometer (Philips PW 1390) using $\mathrm{Cu} \mathrm{K} \alpha 1$ as an X-ray source. A thermogravimetric analyzer (TGA Q50) was used to study the thermal behavior of $\mathrm{ZnO}$ NCs and the $\mathrm{ZnO} / \mathrm{GO}$ nanocomposites in the temperature range from 0 to $700{ }^{\circ} \mathrm{C}$ with a heating rate of $10^{\circ} \mathrm{C} \mathrm{min}-1$ in a $40 \mathrm{~mL} \mathrm{~min}^{-1}$ nitrogen flow.

\section{Sensor preparation}

Nano-sensors were prepared by thoroughly mixing $75 \mathrm{mg}$ $\mathrm{ZnO} / \mathrm{GO}$ and $675 \mathrm{mg}$ synthetic carbon powder with $0.2 \mathrm{~mL}$ paraffin oil in a small agate mortar. A portion of the paste was then packed into the tip of the electrode assembly with a surface area of $\left(0.3 \mathrm{~cm}^{2}\right)$ [24]. Electrode surface regeneration was performed before each experiment by polishing 


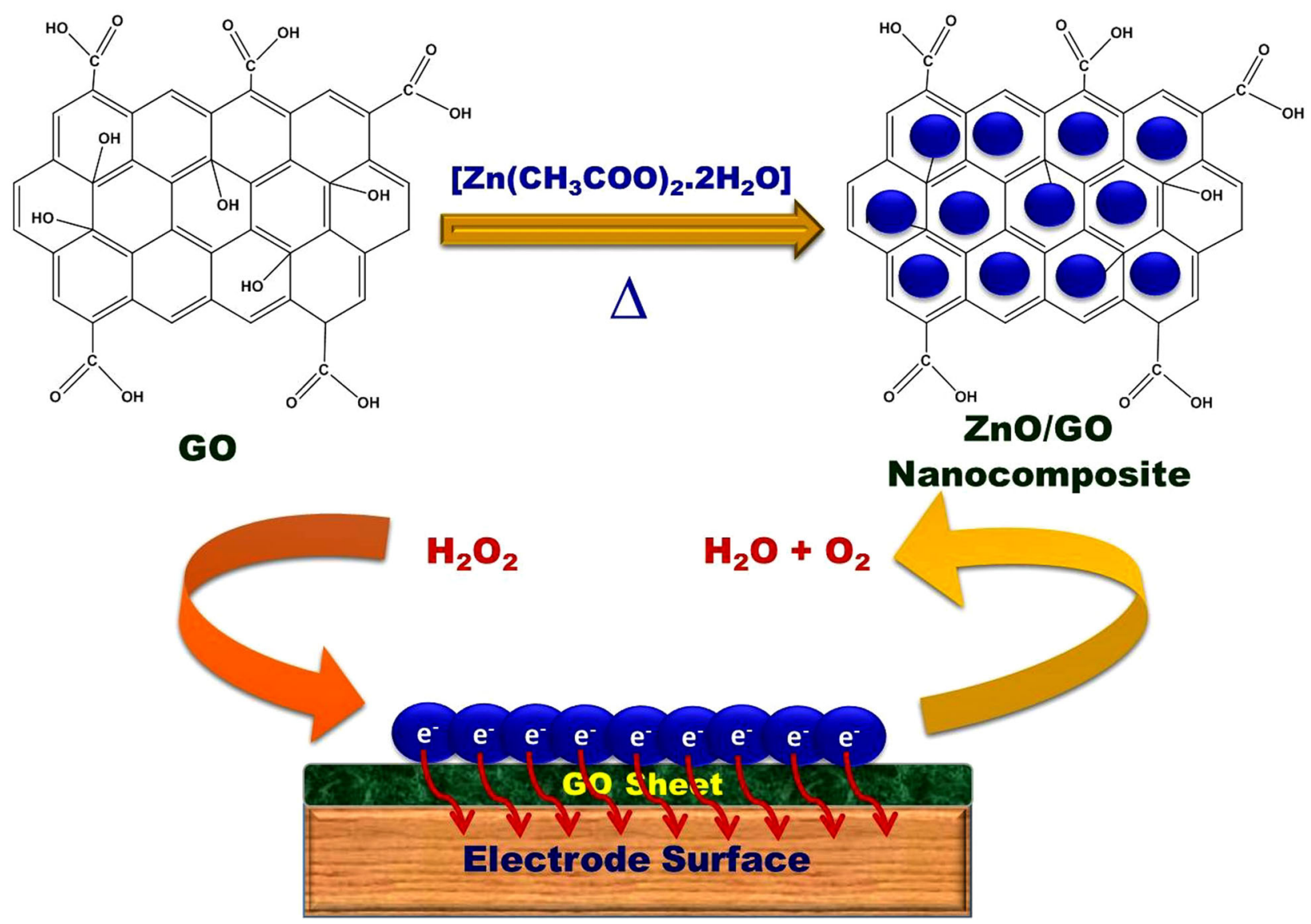

Scheme 1 A schematic illustration of the preparation of the $\mathrm{ZnO} / \mathrm{GO}$ nanocomposite and the fabrication of the sensor's electrode

it with a smooth wet filter paper until a shiny and clean electrode surface was obtained. The fabrication of the $\mathrm{ZnO} /$ GO-based nano-sensor is illustrated in Scheme 1.

\section{Electrochemical characterization of $\mathrm{ZnO} / G O$ nanocomposite}

All electrochemical measurements were performed using a computer controlled Gamry Potentiostat/Galvanostat/ZRA G750, which was connected to a three electrode system comprising of a CPE working electrode, a Pt disc auxiliary electrode, and an $\mathrm{Ag} / \mathrm{AgCl}$ reference electrode. Prior to the measurements, the working electrode was electrochemically activated in $0.1 \mathrm{M} \mathrm{KCl}$ by 10-cyclic scans from -0.2 to $1.0 \mathrm{~V}$ with scan rate of $100 \mathrm{mVs}^{-1}$. Aliquots of the FCN were introduced into the electrochemical cell containing $30 \mathrm{~mL}$ of $\mathrm{KCl}$.

\section{Direct electrochemical detection of $\mathrm{H}_{2} \mathrm{O}_{2}$}

The surface of the nanocomposite sensor was activated in phosphate buffer ( $\mathrm{pH} 7.4$ ) by 10-cyclic scans from -0.2 to $1.0 \mathrm{~V}$ with a scan rate of $100 \mathrm{mVs}^{-1}$. Then, certain amounts of $\mathrm{H}_{2} \mathrm{O}_{2}$ were introduced into the electrochemical cell containing $30 \mathrm{~mL}$ of phosphate buffer. All the experiments were carried out at room temperature.

\section{Results and discussion}

\section{Structural features of $\mathrm{ZnO} / \mathrm{GO}$ nanocomposite}

The morphological characterizations of the synthesized $\mathrm{GO}$, and $\mathrm{ZnO} / \mathrm{GO}$ nanocomposite were examined by FESEM. Figure 1a shows the basic shape of GO sheet that was significantly exfoliated, and looks like pieces of leaves with a dimension ranging from several hundred $\mathrm{nm}$ to several microns. Figure $1 \mathrm{~b}$ shows the top view of $\mathrm{ZnO} / \mathrm{GO}$ nanocomposite which indicates that $\mathrm{ZnO} \mathrm{NCs}$ are closely anchored at the surface of GO.

From the TEM images, the GO surface looks smooth and integrated (Fig. 2a). In the case of $\mathrm{ZnO} / \mathrm{GO}$ nanocomposite (Fig. 2b), a large number of $\mathrm{ZnO}$ NCs with average diameters $21.7 \pm 2.3 \mathrm{~nm}$ were observed uniformly on the surface of the GO. The arrows clearly show the edges of the GO sheet. The high magnification TEM image 

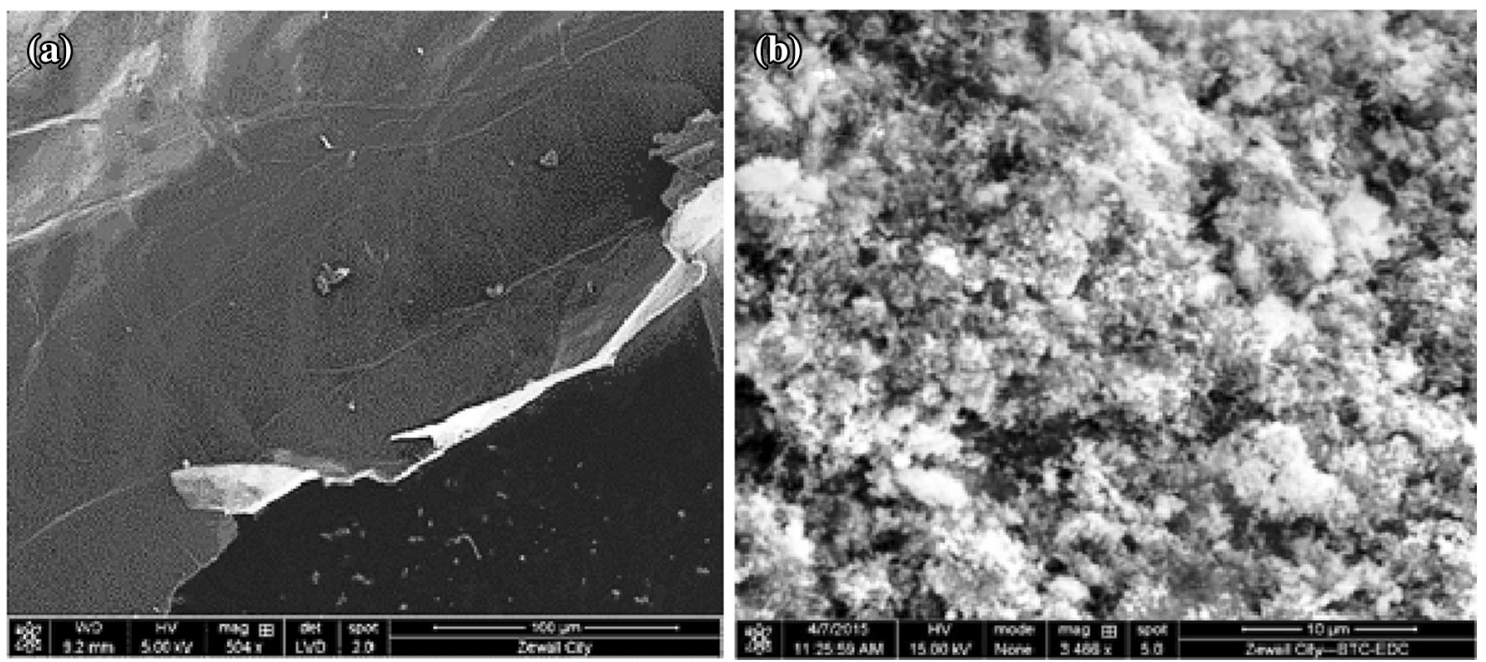

Fig. 1 FESEM of a GO, and b $\mathrm{ZnO} / \mathrm{GO}$ nanocomposite
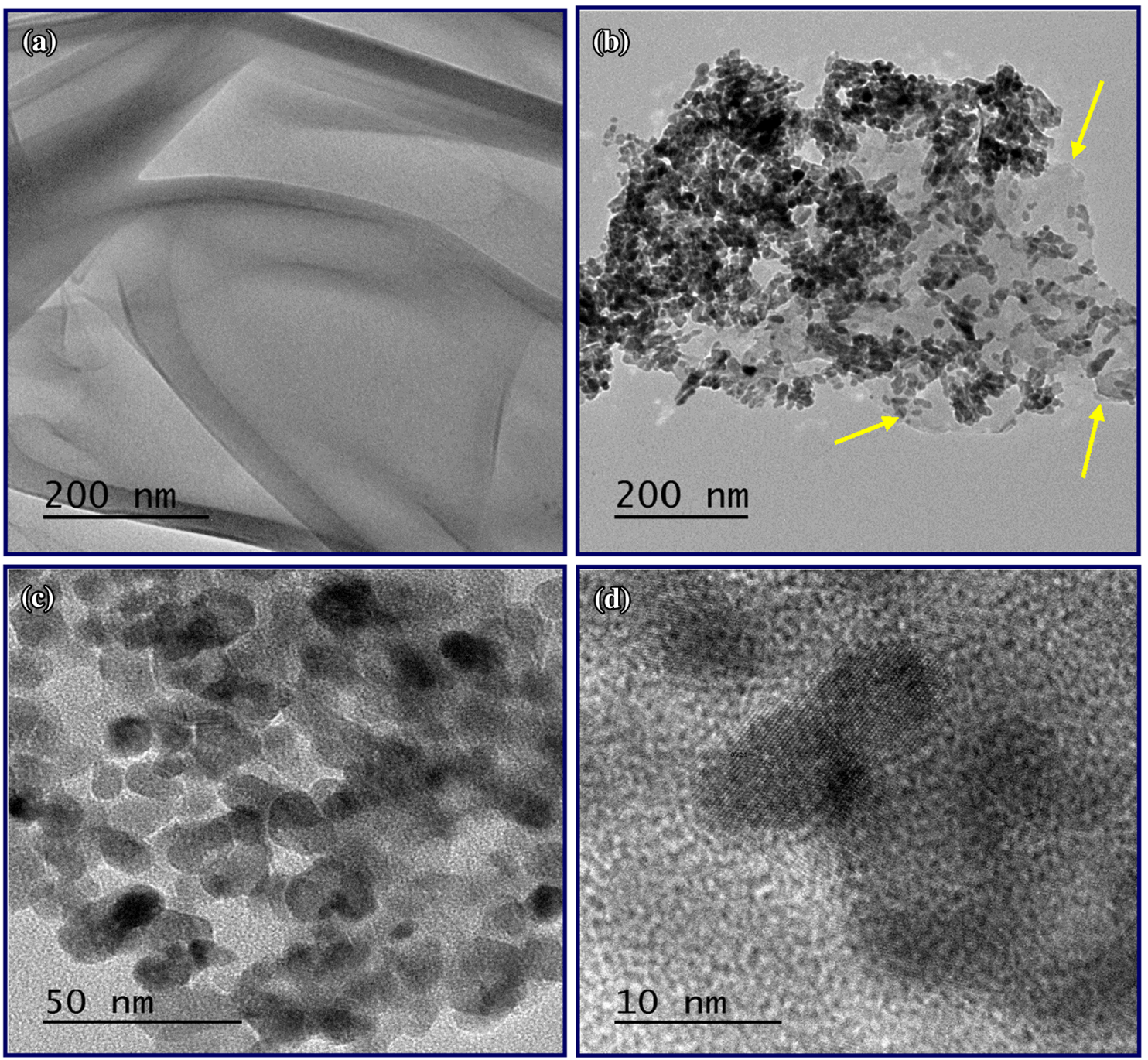

Fig. 2 TEM images of a GO, b, $\mathbf{c} \mathrm{ZnO} / \mathrm{GO}$ nanocomposite with different magnifications, and d HRTEM image of ZnO NCs anchored GO surface 


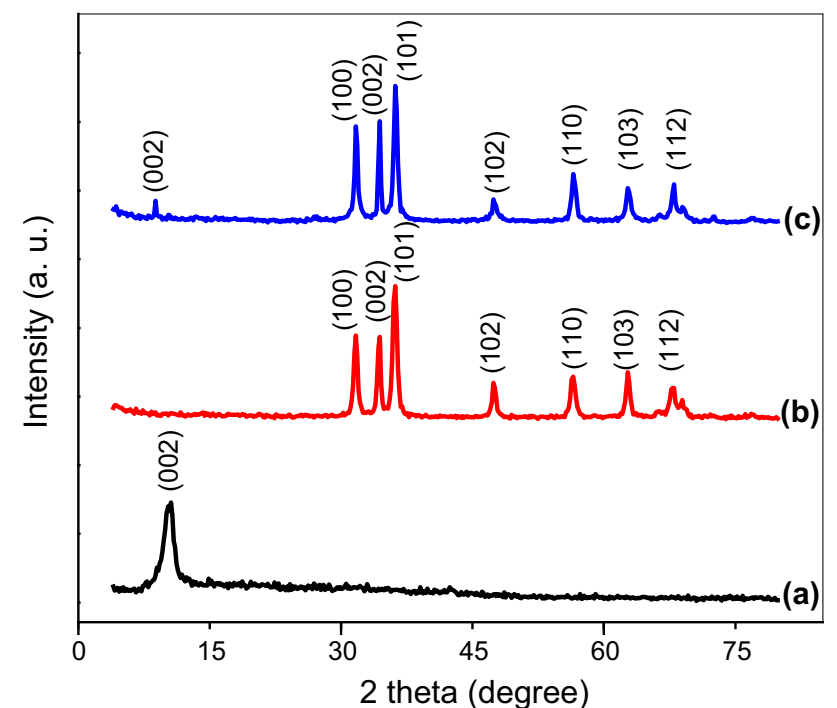

Fig. $3 \mathrm{XRD}$ patterns of $a \mathrm{GO}, b \mathrm{ZnO} \mathrm{NCs}$, and $c \mathrm{ZnO} / \mathrm{GO}$ nanocomposite

(Fig. 2c) further reveals that $\mathrm{ZnO}$ NCs are almost spherical in shape. The high-resolution transmission electron microscopy (HRTEM) image of the ZnO NCs (Fig. 2d) shows a clear lattice fringe which indicates a high degree of crystallinity of the $\mathrm{ZnO}$.

Furthermore, the XR diffraction patterns of $\mathrm{GO}, \mathrm{ZnO}$ $\mathrm{NCs}$ and $\mathrm{ZnO} / \mathrm{GO}$ nanocomposite are illustrated in (Fig. 3). In the diffractogram of GO (Fig. 3a), the peak appearing at $10.6^{\circ}$ is due to the presence of oxygen carrying groups on the GO-surface. This peak was significantly decreased in $\mathrm{ZnO} / \mathrm{GO}$ nanocomposite (Fig. 3c) due to exfoliation of GO sheet as a result of the $\mathrm{ZnO}$ NCs surface loading. As obvious from (Figs. 3b, c), a coincidence of diffraction peaks for $\mathrm{ZnO} \mathrm{NCs}$ and $\mathrm{ZnO} / \mathrm{GO}$ nanocomposite is highly remarkable indicating the formation of well crystalline structure of $\mathrm{ZnO}$ NCs onto the GO surface. Peaks at $31.7^{\circ}$, $34.4^{\circ}, 36.2^{\circ}, 47.4^{\circ}, 56.6^{\circ} 62.9^{\circ}, 65.5^{\circ}, 68.0^{\circ}$ and $69.1^{\circ}$ that are corresponding to (100), (002), (101), (102), (110), (103), (200), (112) and (201) lattice planes, respectively, indicating the formation of wurtzite structure with $2 \mathrm{D}$ hexagonal $P 6_{3} m c$ space group $[25,26]$.

For the functional analysis, FTIR-ATR spectra were used as shown in Fig. 4. The following functional groups were identified; O-H stretching vibrations $\left(3240-3300 \mathrm{~cm}^{-1}\right)$, $\mathrm{C}=\mathrm{O}$ stretching vibration $\left(1720-1740 \mathrm{~cm}^{-1}\right), \mathrm{C}=\mathrm{C}$ from unoxidized $s p^{2} \mathrm{C}-\mathrm{C}$ bonds $\left(1590-1620 \mathrm{~cm}^{-1}\right)$, and $\mathrm{C}-\mathrm{O}$ vibrations $\left(1250 \mathrm{~cm}^{-1}\right)$ [23]. Comparing the spectra of $\mathrm{ZnO} /$ GO nanocomposite with that of GO demonstrates a slight shift with a reduction in the intensity of the $\mathrm{O}-\mathrm{H}$ peak (at $3240 \mathrm{~cm}^{-1}$ ). Besides, the peak at about $1740 \mathrm{~cm}^{-1-}$ corresponding to the $\mathrm{C}=\mathrm{O}$ was disappeared in $\mathrm{ZnO} / \mathrm{GO}$ nanocomposite. This confirms the formation of $\mathrm{ZnO} \mathrm{NCs}$

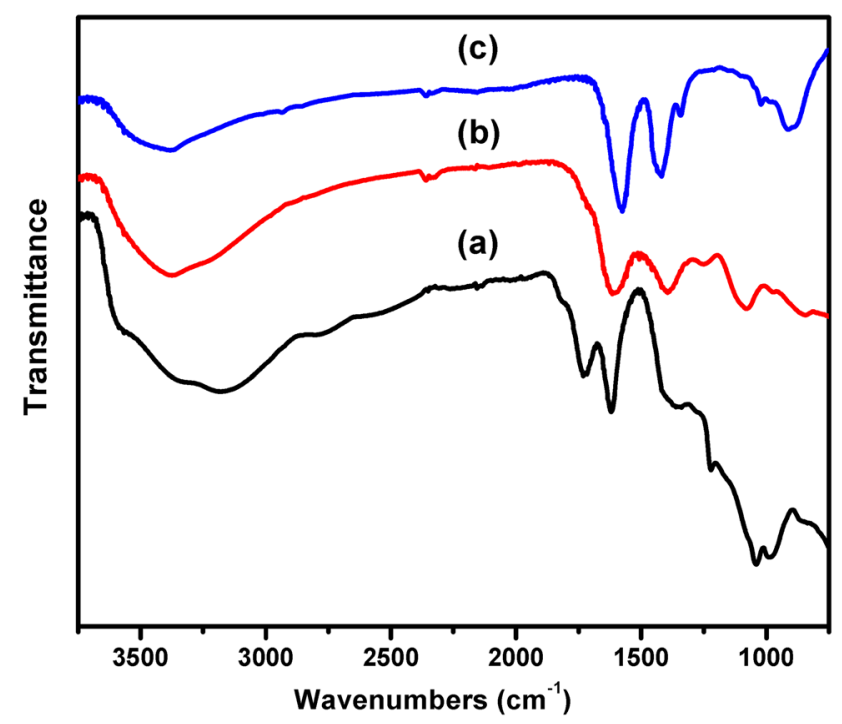

Fig. 4 FTIR-ATR spectra of $a \mathrm{GO}, b \mathrm{ZnO} / \mathrm{GO}$ nanocomposite, and $c \mathrm{ZnO} \mathrm{NCs}$

onto the surface of GO accompanied by a partial reduction of the GO. For further physical investigations, thermal gravimetric analysis has been performed (see Fig. 1 in the supplementary information).

\section{Electrocatalytic activity of $\mathrm{ZnO} / \mathrm{GO}$}

Carbon paste electrode was used in this study due to its ease of fabrication, modification and renewability of its active surface area. For achieving better direct electrochemical detection and identifying the role of the nanocomposite, different electrodes, $\mathrm{ZnO}, \mathrm{ZnO} / \mathrm{GO}$ nanocomposite or unmodified electrode, were prepared and their electrochemical responses were measured. In this regard, Ferricyanide (FCN) was used for testing the electrocatalytic performance of the prepared sensors. Therefore, the redox reactions of FCN using the modified and unmodified electrodes were obtained. As shown in Fig. 5a, the electrochemical peak currents, either the oxidation or the reduction peaks, increased after incorporating the nanomaterials, either $\mathrm{ZnO}$ or $\mathrm{ZnO} / \mathrm{GO}$, into the electrode matrix. However, the addition of $\mathrm{ZnO} / \mathrm{GO}$ nanocomposite exhibited the highest electrochemical signals.

Due to the catalytic properties of graphene oxides, the conjugation of $\mathrm{GO}$ to the $\mathrm{ZnO}$ nanoparticles enhanced the electron transfer. GO role in the composite could be demonstrated as a wire-transfer for bridging the electron between the $\mathrm{ZnO}$ (that accepts the electrons from the redox molecules) and the electrode surface.

Consequently, the effect of $\mathrm{ZnO} / \mathrm{GO}$ nanocomposite concentrations, within the electrode matrix, on the 

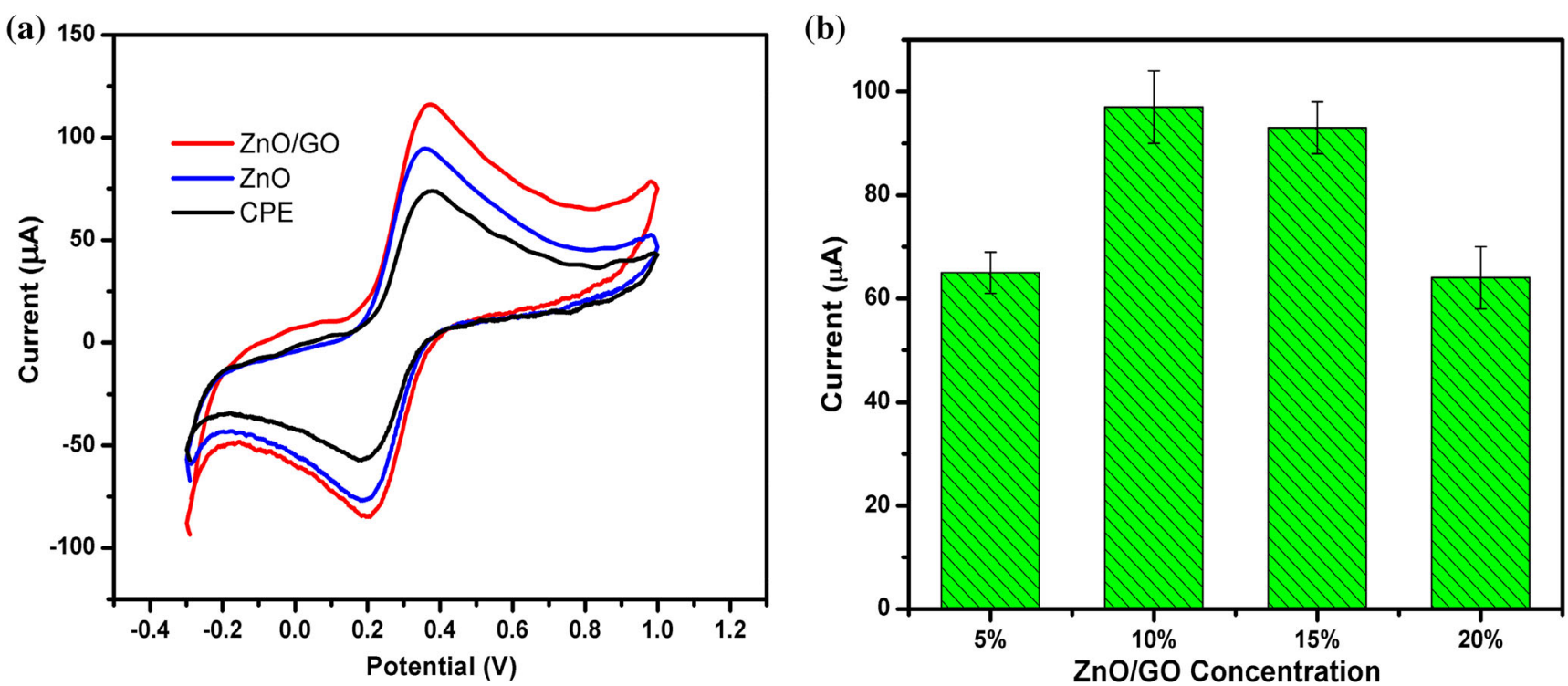

Fig. 5 a Cyclic voltammograms of different electrodes against $\mathrm{FCN}(2 \mathrm{mM})$ in $\mathrm{KCl}(0.1 \mathrm{M})$, b effect of $\mathrm{ZnO} / \mathrm{GO}$ concentration on the electrochemical performance of FCN

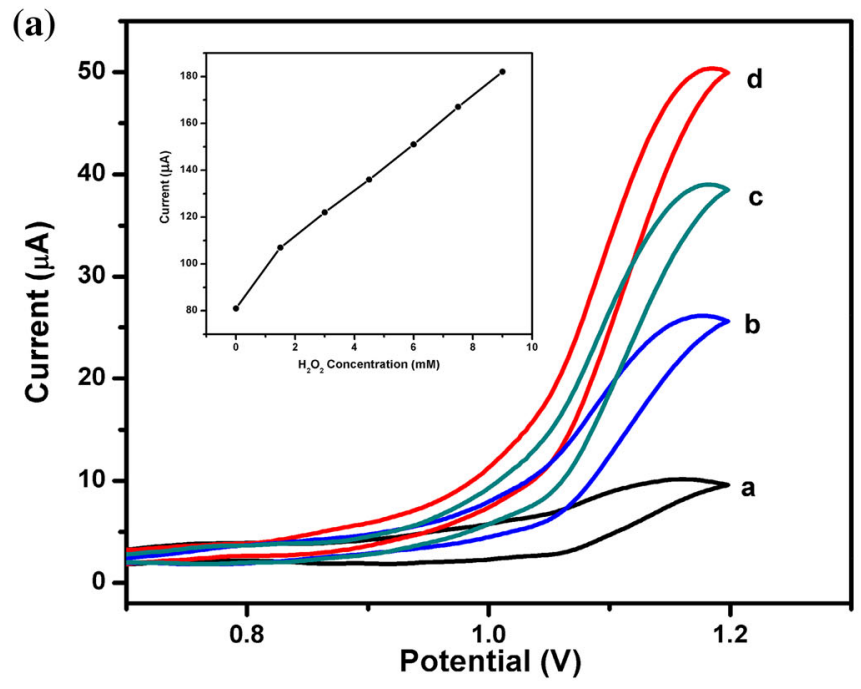

Fig. 6 a Cyclic voltammograms obtained at $\mathrm{ZnO} / \mathrm{GO} / \mathrm{CPE}$ in the $a$ absence, and presence of $b 1.5 \mathrm{mM}, c 3 \mathrm{mM}$, and $d 4.5 \mathrm{mM} \mathrm{H}_{2} \mathrm{O}_{2}$, The inset is the corresponding calibration curve between the current

measurable oxidation current of FCN was investigated (Fig. 5b). Specifically, different concentrations ranging from 5 to $20 \%(\mathrm{w} / \mathrm{w})$ were selected. As shown in (Fig. 5b), the electrochemical signal of the $10 \% \mathrm{w} / \mathrm{w}$ was found to be the highest. To that end, $10 \% \mathrm{w} / \mathrm{w}$ of $\mathrm{ZnO} / \mathrm{GO}$ nanocomposite was selected as optimal concentration. Moreover, the impact of FCN concentration was examined against $10 \% \mathrm{w} / \mathrm{w}$ of $\mathrm{ZnO} / \mathrm{GO}$ nanocomposite (see Fig. 2 in the supplementary information) and the results showed increase in electrochemical response with the increase of FCN concentration.

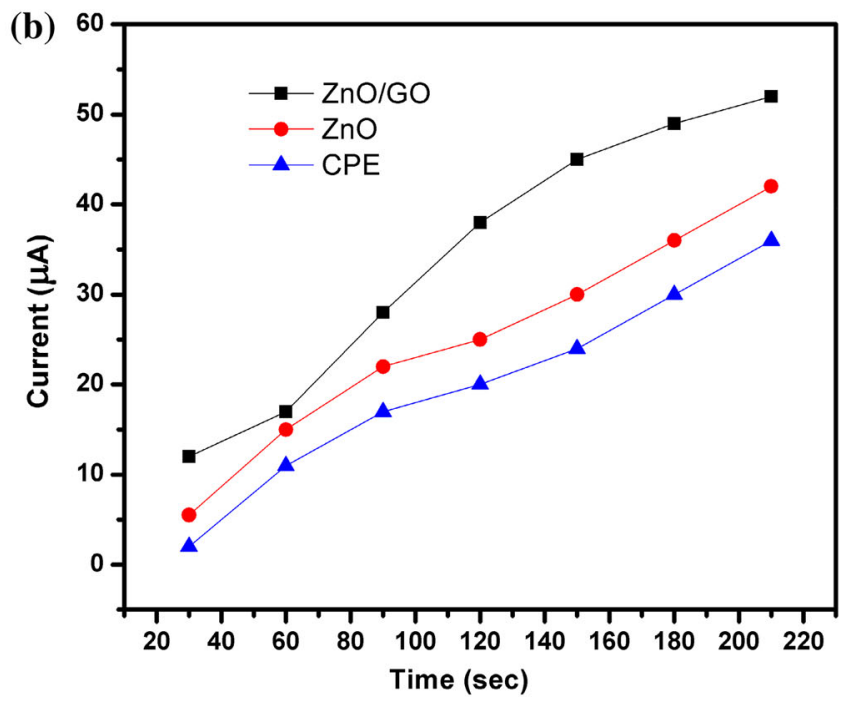

response and concentration of $\mathrm{H}_{2} \mathrm{O}_{2}$. b Amperometric response of different electrodes against $\mathrm{H}_{2} \mathrm{O}_{2}$

\section{The use of $\mathrm{ZnO} / \mathrm{GO}$-based sensor for $\mathrm{H}_{2} \mathrm{O}_{2}$ detection}

As the main concern of this study is to enable the direct detection of $\mathrm{H}_{2} \mathrm{O}_{2}$ using the developed nano-structured electrode, the capability of direct electron transfer was tested. In this regards, different concentrations of peroxides were injected into the electrochemical cell and the possibility of direct oxidation was measured. As shown in Fig. 6 , the oxidation peak currents of $\mathrm{H}_{2} \mathrm{O}_{2}$ at $\sim 1.1 \mathrm{~V}$ were obtained without the addition of artificial redox mediator. However, the chronoamperometric responses of 
the nano-composite were much higher than that obtained by either the $\mathrm{ZnO}$-based electrode or the bare-CPE.

Therefore, the used nanostructured electrode has the enough electrocatalytic activity to enable the direct detections of peroxide. In addition, the oxidation currents were correlated with the concentrations of $\mathrm{H}_{2} \mathrm{O}_{2}$ which reflects the sensitivity as well as the reliability of the proposed sensor.

\section{Effect of pH}

Figure 7 shows the influence of $\mathrm{pH}$ on the performance of the $\mathrm{ZnO} / \mathrm{GO}$ modified electrode surface towards the oxidation of peroxides. It was found that the oxidation current

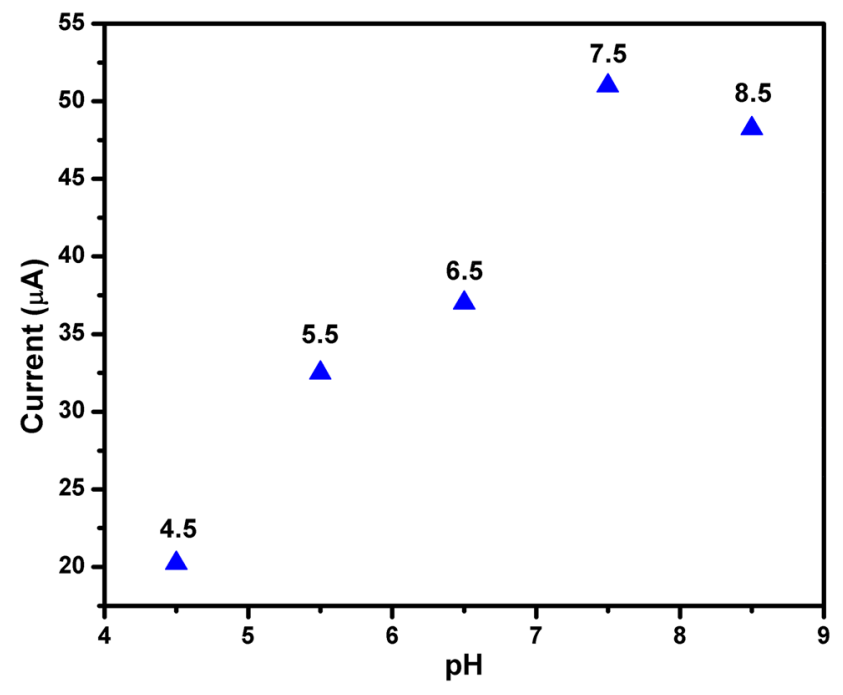

Fig. 7 Effect of $\mathrm{pH}$ on the oxidation peak of the composite-modified electrode in $0.1 \mathrm{M}$ PBS

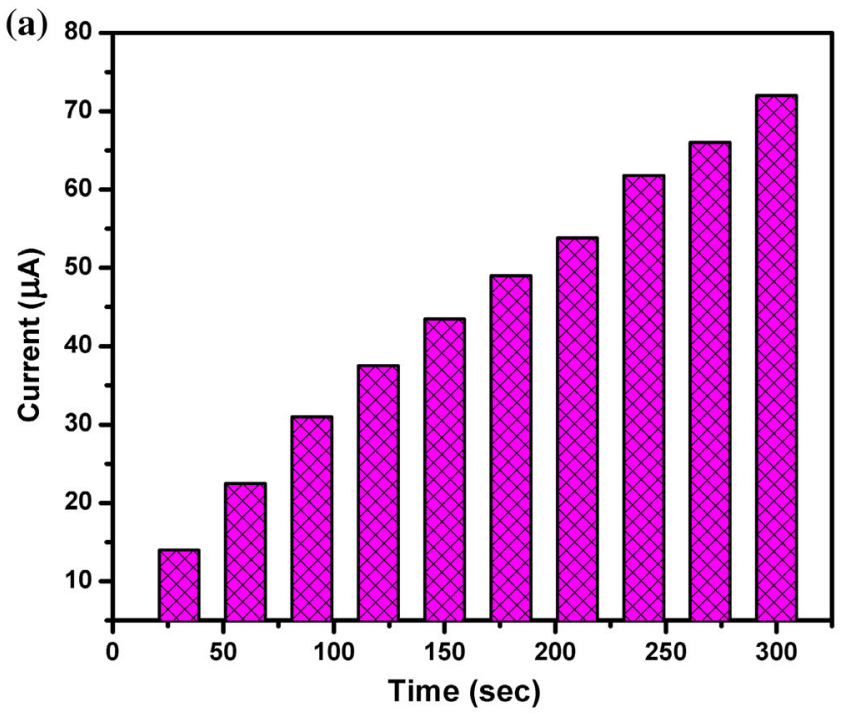

increased by increasing the $\mathrm{pH}$ values until reaching 7.4 which have the highest peak, after that the peak height decreased. The decreasing of oxidation current at lower $\mathrm{pH}$ may be attributed to the protonation of the electrode surface which resists the electron transfer. Therefore, PBS at pH 7.4 was selected as the supporting electrolyte in all subsequent experiments, given that the biosensors would be used under normal physiological conditions [27].

\section{Chronoamperometric determinations of peroxide}

Using the CVs measurements, the capability of direct oxidation of peroxide using the nanostructured electrode was confirmed. Consequently, the chronoamperometric measurements were performed at $1.1 \mathrm{~V}$ versus $\mathrm{Ag} / \mathrm{AgCl}$. A standard addition was done by adding a certain concentration of $\mathrm{H}_{2} \mathrm{O}_{2}$ at fixed time intervals $(30 \mathrm{~s})$. From the time/ current curve (Fig. 8a), a fast response towards each addition was noted, which reflects the rapid electron transfer as well as the electrocatalytic power of the developed nanostructured electrode. Figure $8 \mathrm{~b}$ shows the corresponding calibration curve that has a linear response range from 1 to $15 \mathrm{mM}$ with the detection limit $(\mathrm{S} / \mathrm{N}=3)$ of $0.8 \mathrm{mM}$. Method sensitivity for the real physiological concentration of peroxides in the biological samples is sufficient.

\section{Conclusion}

In this study, we have reported a facile and cost-effective approach for the fabrication of $\mathrm{ZnO} \mathrm{NCs}$ on the GO surface. The resulting $\mathrm{ZnO} / \mathrm{GO}$ nanocomposite was

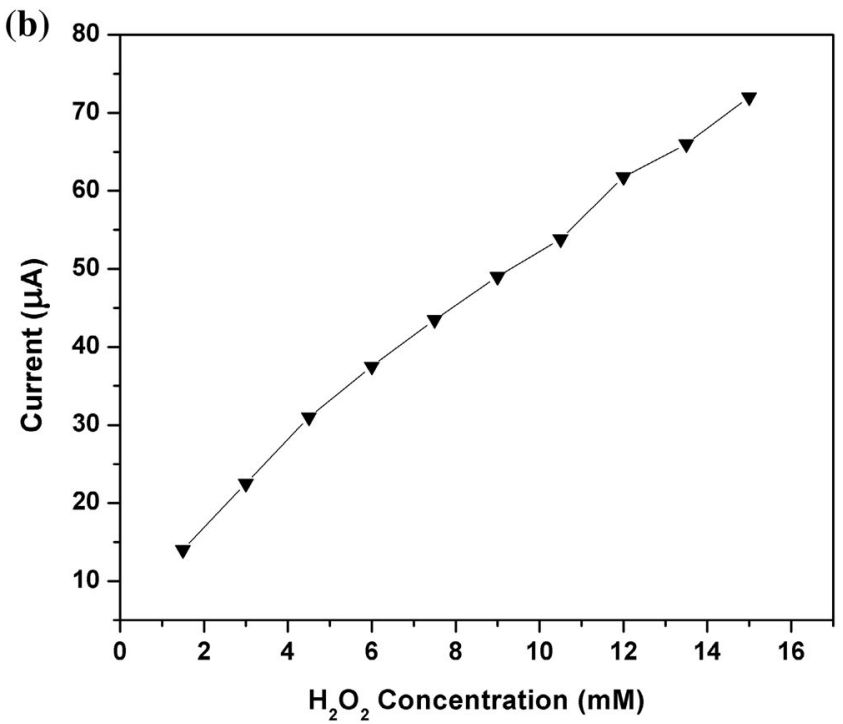

Fig. 8 a Amperometric response of the $\mathrm{ZnO} / \mathrm{GO}$ electrode upon addition of $\mathrm{H}_{2} \mathrm{O}_{2}$ at $1.1 \mathrm{~V}$. b The corresponding calibration curve between the current response and concentration of $\mathrm{H}_{2} \mathrm{O}_{2}$ 
incorporated into the carbon paste electrode matrix producing a significant improvement in the electrical conductivity, electrocatalytic activity which provides a direct electrochemical detection of superoxide. The effect of $\mathrm{ZnO} / \mathrm{GO}$ nanocomposite concentrations incorporated into the electrode was investigated and it was found that $10 \%$ $(w / w)$ has the highest electrochemical signal. These results revealed that the developed nanocomposite with the high surface area and electrocatalytic activity offers great promise for a non-enzymatic biosensor.

Acknowledgments The authors are grateful for the group leader of Biological Systems Analysis, Prof. Dr. Ursula (Bilitewski, Helmholtz Centre for Infection Research, HZI, and Braunschweig, Germany) for presenting the Potentiostat (Gamry Potentiostat/Galvanostat/ZRA G750).

\section{Compliance with ethical standards}

Conflict of interest The authors declare that there are no conflicts of interest.

Open Access This article is distributed under the terms of the Creative Commons Attribution 4.0 International License (http://crea tivecommons.org/licenses/by/4.0/), which permits unrestricted use, distribution, and reproduction in any medium, provided you give appropriate credit to the original author(s) and the source, provide a link to the Creative Commons license, and indicate if changes were made.

\section{References}

1. Thenmozhi, K., Narayanan, S.S.: Electrochemical sensor for $\mathrm{H}_{2} \mathrm{O}_{2}$ based on thionin immobilized 3-aminopropyltrimethoxy silane derived sol-gel thin film electrode. Sens. Actuators B Chem. 125, 195-201 (2007)

2. Shen, G., Chen, P.C., Ryu, K., Zhou, C.: Devices and chemical sensing applications of metal oxide nanowires. J. Mater. Chem. 19, 828-839 (2009)

3. Chu, D., Masuda, Y., Ohji, T., Kato, K.: Formation and photocatalytic application of $\mathrm{ZnO}$ nanotubes using aqueous solution. Langmuir 26, 2811-2815 (2009)

4. Willander, M., Nur, O., Zhao, Q., Yang, L., Lorenz, M., Cao, B., et al.: Zinc oxide nanorod based photonic devices: recent progress in growth, light emitting diodes and lasers. Nanotechnology 20, 332001 (2009)

5. Pearton, S., Norton, D., Heo, Y., Tien, L., Ivill, M., Li, Y., et al.: $\mathrm{ZnO}$ spintronics and nanowire devices. J. Electron. Mater. 35, 862-868 (2006)

6. Godlewski, M., Guziewicz, E., Kopalko, K., Łuka, G., Łukasiewicz, M., Krajewski, T., et al.: Zinc oxide for electronic, photovoltaic and optoelectronic applications. Low Temp. Phys. 37, 235-240 (2011)

7. Özgür, Ü., Alivov, Y.I., Liu, C., Teke, A., Reshchikov, M., Doğan, S., et al.: A comprehensive review of $\mathrm{ZnO}$ materials and devices. J. Appl. Phys. 98, 041301 (2005)

8. Janotti, A., Van de Walle, C.G.: Native point defects in $\mathrm{ZnO}$. Phys. Rev. B 76, 165202 (2007)

9. Schulz, P., Kelly, L.L., Winget, P., Li, H., Kim, H., Ndione, P.F., et al.: Tailoring electron-transfer barriers for zinc oxide/C60 fullerene interfaces. Adv. Funct. Mater. 24, 7381-7389 (2014)
10. Xie, L., Xu, Y., Cao, X.: Hydrogen peroxide biosensor based on hemoglobin immobilized at graphene, flower-like zinc oxide, and gold nanoparticles nanocomposite modified glassy carbon electrode. Colloids Surf. B Biointerfaces 107, 245-250 (2013)

11. Chawla, S., Pundir, C.S.: An amperometric hemoglobin A1c biosensor based on immobilization of fructosyl amino acid oxidase onto zinc oxide nanoparticles-polypyrrole film. Anal. Biochem. 430, 156-162 (2012)

12. Zhou, F., Zhao, X., Zheng, H., Shen, T., Tang, C.: Synthesis and electrochemical properties of $\mathrm{ZnO} 3 \mathrm{D}$ nanostructures. Chem. Lett. 34, 1114-1115 (2005)

13. Palanisamy, S., Cheemalapati, S., Chen, S.M.: Highly sensitive and selective hydrogen peroxide biosensor based on hemoglobin immobilized at multiwalled carbon nanotubes-zinc oxide composite electrode. Anal. Biochem. 429, 108-115 (2012)

14. Wang, H., Pan, Q., Cheng, Y., Zhao, J., Yin, G.: Evaluation of $\mathrm{ZnO}$ nanorod arrays with dandelion-like morphology as negative electrodes for lithium-ion batteries. Electrochim. Acta 54, 2851-2855 (2009)

15. Kang, C.G., Kang, J.W., Lee, S.K., Lee, S.Y., Cho, C.H., Hwang, H.J., et al.: Characteristics of CVD graphene nanoribbon formed by a ZnO nanowire hardmask. Nanotechnology 22, 295201 (2011)

16. Wan, Y., Wang, Y., Wu, J., Zhang, D.: Graphene oxide sheetmediated silver enhancement for application to electrochemical biosensors. Anal. Chem. 83, 648-653 (2011)

17. Wang, J., Li, Y., Ge, J., Zhang, B.P., Wan, W.: Improving photocatalytic performance of $\mathrm{ZnO}$ via synergistic effects of $\mathrm{Ag}$ nanoparticles and graphene quantum dots. Phys. Chem. Chem. Phys. 17, 18645-18652 (2015)

18. Yang, K., Xu, C., Huang, L., Zou, L., Wang, H.: Hybrid nanostructure heterojunction solar cells fabricated using vertically aligned $\mathrm{ZnO}$ nanotubes grown on reduced graphene oxide. Nanotechnology 22, 405401 (2011)

19. Geng, W., Zhao, X., Zan, W., Liu, H., Yao, X.: Effects of the electric field on the properties of $\mathrm{ZnO}$-graphene composites: a density functional theory study. Phys. Chem. Chem. Phys. 16, 3542-3548 (2014)

20. Chen, J., Li, C., Eda, G., Zhang, Y., Lei, W., Chhowalla, M., et al.: Incorporation of graphene in quantum dot sensitized solar cells based on $\mathrm{ZnO}$ nanorods. Chem. Commun. 47, 6084-6086 (2011)

21. Erman, J.E., Vitello, L.B., Mauro, J.M., Kraut, J.: Detection of an oxyferryl porphyrin. pi.-cation-radical intermediate in the reaction between hydrogen peroxide and a mutant yeast cytochrome $\mathrm{c}$ peroxidase. Evidence for tryptophan-191 involvement in the radical site of compound I. Biochemistry 28, 7992-7995 (1989)

22. Zhou, M., Diwu, Z., Panchuk-Voloshina, N., Haugland, R.P.: A stable nonfluorescent derivative of resorufin for the fluorometric determination of trace hydrogen peroxide: applications in detecting the activity of phagocyte NADPH oxidase and other oxidases. Anal. Biochem. 253, 162-168 (1997)

23. Marcano, D.C., Kosynkin, D.V., Berlin, J.M., Sinitskii, A., Sun, Z., Slesarev, A., et al.: Improved synthesis of graphene oxide. ACS Nano 4, 4806-4814 (2010)

24. Hassan, R.Y., Bilitewski, U.: Direct electrochemical determination of Candida albicans activity. Biosens. Bioelectron. 49, 192-198 (2013)

25. Bindu, P., Thomas, S.: Estimation of lattice strain in $\mathrm{ZnO}$ nanoparticles: X-ray peak profile analysis. J. Theor. Appl. Phys. 8, 123-134 (2014)

26. Janotti, A., Van de Walle, C.G.: Fundamentals of zinc oxide as a semiconductor. Rep. Prog. Phys. 72, 126501 (2009)

27. Butwong, N., Zhou, L., Moore, E., Srijaranai, S., Luong, J.H., Glennon, J.D.: A highly sensitive hydrogen peroxide biosensor based on hemoglobin immobilized on cadmium sulfide quantum dots/chitosan composite modified glassy carbon electrode. Electroanalysis 26, 2465-2473 (2014) 